\title{
DIRECT LABORATORY TENSILE TESTING OF SELECT YIELDING ROCK BOLT SYSTEMS
}

\author{
by \\ John D. VandeKraats and Sanford O. Watson \\ Westinghouse Electric Corporation \\ Waste Isolation Division \\ PO Box 2078 \\ Carlsbad, New Mexico 88221-2078
}

\begin{abstract}
Yielding rock boit support systems have been developed to accommodate ground movement in shifting ground such as in coal operations; in creeping ground such as salt, trona, and potash: and in swelling ground associated with some clays. These systems, designed to remain intact despite ground movement, should enhance mine safety and help contain costs in areas where rebolting of rigid non-yielding systems is typically required. Four such systems were tested in straight tensile pulls in the laboratory. They include the Slip Nut System from Dywidag Systems International USA, Inc., Ischebeck's bolt mounted Titan Load Indicator, Rocky Mountain Bolt Company's Yielding Cable Bolt, and a rock bolt installed variation of the yielding steel post developed by RE/SPEC Inc. The first two systems are currently marketed products and the latter two are prototype systems.
\end{abstract}

Each system responds to load and displacement by yielding in a unique manner. All are designed to yield at predetermined loads. A description of each system and its yield function is provided.

Each system was tested over its prescribed yield range in a test machine. At least five tests were performed on each system. Each system yielded and continued to provide support according to its design. Each shows promise for ground control use in shifting or creeping rock. This work helps to illustrate the comparative differences in performance between these specialized systems and the applications where they may be most useful.

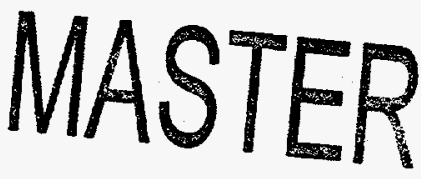

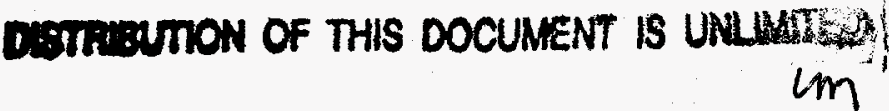

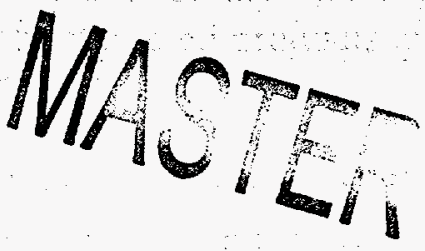




\section{DISCLAIMER}

Portions of this document may be illegible in electronic image products. Images are produced from the best available original document. 


\section{INTRODUCTION}

Yielding rock bolt support systems have been developed to accommodate movement in shifting ground found in many coal mining operations; in creeping ground found in salt, trona, and potash mines; and in swelling ground associated with some clays. These systems, designed to remain intact despite ground movement, should enhance mine safety and help contain costs in areas where rebolting of rigid non-yielding systems is typically required. Four such systems were tested in straight tensile pulls in the laboratory. They include the Slip Nut System from Dywidag Systems International USA, Inc. (DSI), Ischebeck's bolt mounted Titan Load Indicator, a rock bolt installed variation of the yielding steel post developed by RE/SPEC Inc., and Rocky Mountain Bolt Company's (RMB) Yielding Cable Bolt. The first two systems are currently marketed products and the latter two are prototype systems.

Each system responds to load and displacement by yielding in a unique manner. All are designed to yield at predetermined loads. Each of the systems is easily monitored in-situ due to the characteristic that yielding components are installed at or near the borehole collar.

\section{SYSTEM DESCRIPTIONS}

Slip Nut System: The DSI slip nuts work on their standard No. 7 ( $22 \mathrm{~mm}$ diameter) grade 60 threadbar. The nut is threaded onto a bar and snugged against its bearing plate (Fig. 1). When load builds to the pre-engineered yield level of $133 \mathrm{kN}$ ( $30 \mathrm{kip})$ as the result of shifting ground or creeping rock, the nut acts as a die and cuts through the thread, reducing the load and coming to rest on the next thread where the process repeats. Slip nuts may be used on single length, threadbars or may be installed on DSI's tensionable cable bolts. Laboratory tests were performed on the tensionable cable bolts. The tensionable cable bolt (Fig. 2) is a Grade 270, seven-strand cable bolt which is coupled to a No. 7 grade 60 threadbar tail.

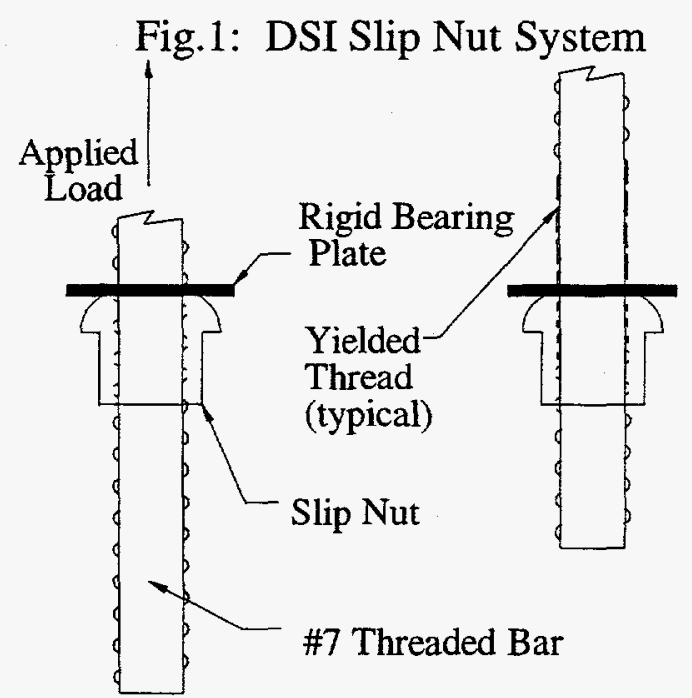

1. Start
2. During Slip Process 
Slip nut installations on either the threaded bar or the tensionable cable bolt require that a tail protrude into the excavation. The length of the tail is a function of the amount of yield. The length protruding into the opening is reduced as the yield process progresses. A stop nut can be installed at the end of the tail to transition into a rigid non-yielding system when the slip nut has yielded the length of the tail. If a stop nut is used, the final tail length will be approximately three inches. If no stop nut is installed, the system will lose all bearing capacity when the slip nut cuts the last thread and falls off the end of the bar.

Fig. 2: DSI Tensionable Cable Bolt with Slip Nut

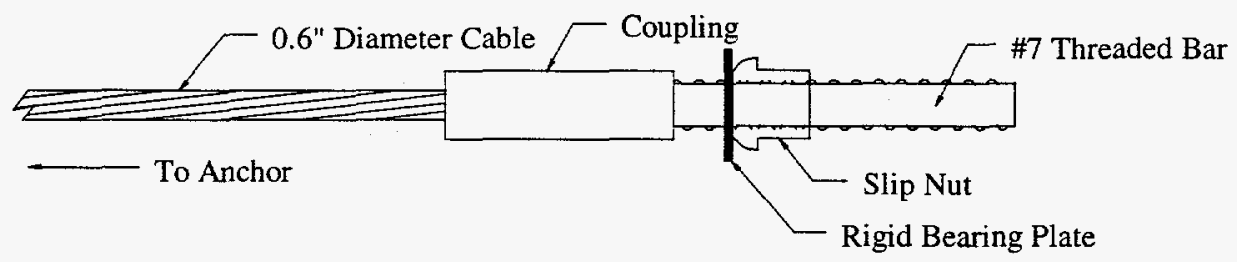

Titan Load Indicator: The Titan Load Indicator is a device that yields at predefined loads. The device is shaped like a thick-walled hollow cylinder with three grooves machined in the outside wall; each has a different depth or wall thickness. The thin walled grooves collapse as increasing load is applied. The groove with the thinnest wall collapses first, followed by the next thicker walled groove, and the thickest walled groove collapses last. The thinnest groove is intended as a prestress groove to be used for load indication at installation. It is designed to close at $60 \mathrm{kN}$ (13 kip). The other two grooves are intended to be used in the working range and are designed to close at a $180 \mathrm{kN}$ (40 kip) working load (Ischebeck, 1994). The yield sequence of a load indicator installed on a threaded bar is illustrated in Fig. 3.

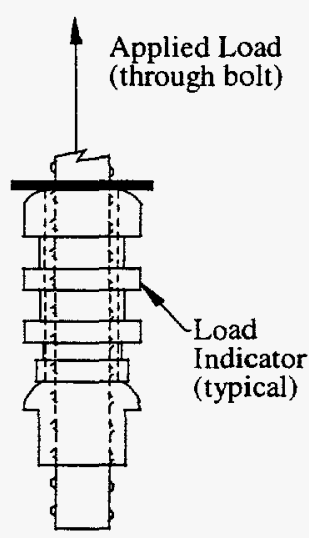

1. Start

\section{Fig. 3: Titan Load Indicator - Yield Sequence}
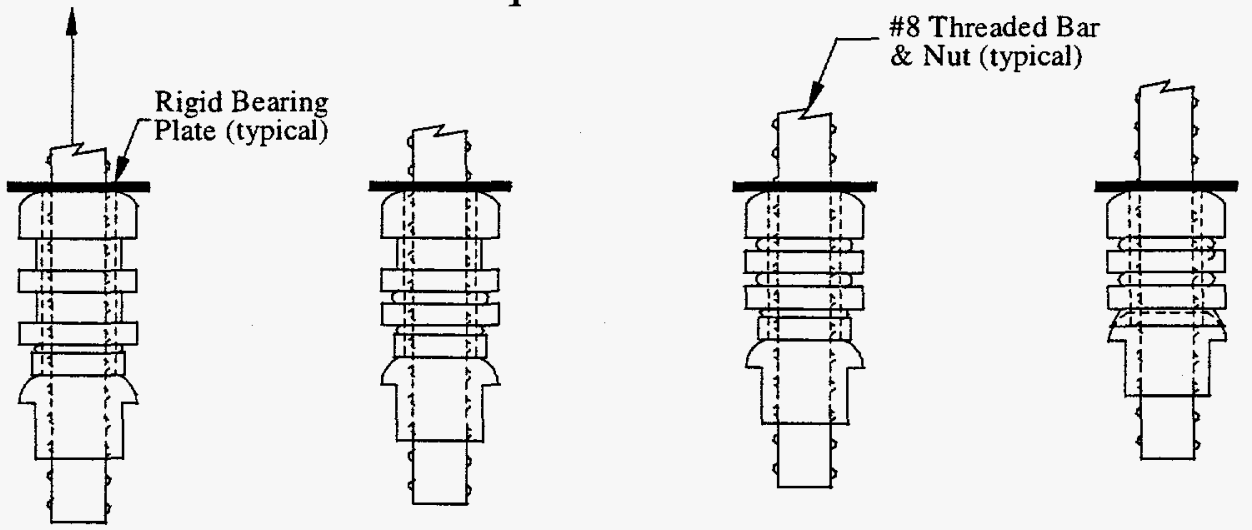

2. 1st Groove Yield
3. 2nd Groove Yield

4. 3rd Groove Yield
5. Flaring of Base 
Since this system is installed at the collar, it will protrude into the excavation, affecting headroom. Load indicators are approximately $0.086 \mathrm{~m}$ (3.4 in.) long initially and have a $0.030 \mathrm{~m}$ (1.18 in.) inside diameter. During the yielding process the length of the indicator is reduced by approximately $0.025 \mathrm{~m}$ (one inch).

Yielding Cable Bolt: This system consists of a seven strand $0.015 \mathrm{~m}$ ( 0.6 inch) diameter grade 270 steel cable inserted through a close fitting pipe (slide chamber). The cable tail has a bullet shaped tube installed over the end of the center strand. Yield is produced as the bolt is loaded and the cable and installed tube are pulled through the slide chamber. Friction generated between the cable and the slide chamber regulates the load during the yielding process (Gillespie, 1993). The yield load can be selected up to the ultimate strength of the cable simply by varying the length of the tube. Bolts with design loads from $94-173 \mathrm{kN}$ (21-39 kip) were tested. The yield length is only limited by the length of the slide chamber. The slide chamber length used in the prototypes tested was $0.51 \mathrm{~m}$ ( 20 inches). Sketches of the bolt (Fig. 4.) and details of the friction components (Fig. 5) follow.

\section{Fig. 4: Rocky Mountain Bolt Company Yielding Cable Bolt}

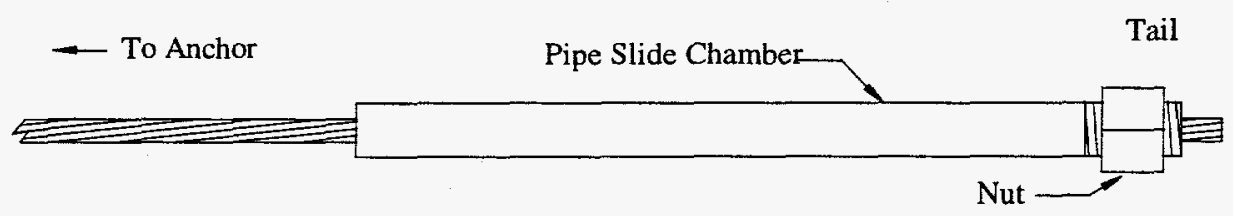

Fig. 5: Details of Friction Component

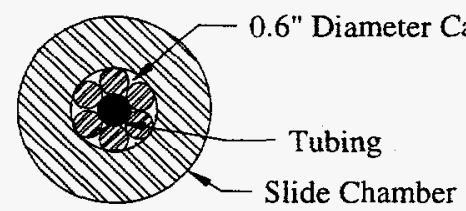

End Section Slide Chamber and Cable

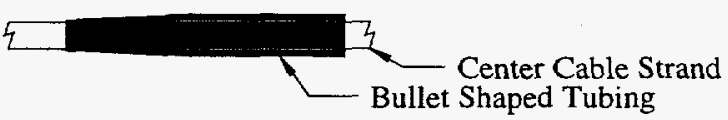

Side Section View Center Strand and Tubing

Headroom is affected only by the short tail and the bearing plate since the slide chamber is inserted into the borehole collar. 
RE/SPEC Collar: The RE/SPEC Yielding Collar is designed with two steel pipes such that one can fit within the other. A "knuckle" is welded then machined smooth on the end of the smaller diameter pipe making it slightly larger than the inside diameter of the larger pipe. The "knuckle" is pressed into the larger pipe. When this device is installed on a rock bolt and load builds, yield is achieved through the frictional slipping of the "knuckle" through the larger pipe. By varying the tolerances different yield characteristics may be obtained. The prototypes tested in Tests 1 and 2 were designed to yield at $89 \mathrm{kN}$ (20 kip) and those in Tests 3-5 were designed to yield at $133 \mathrm{kN}$ ( $30 \mathrm{kip}$ ).

The design yield displacement for the prototypes tested was approximately $0.11 \mathrm{~m} \mathrm{(4} \mathrm{in.),} \mathrm{but} \mathrm{can} \mathrm{be} \mathrm{varied} \mathrm{by} \mathrm{shortening} \mathrm{or} \mathrm{lengthening}$ the pipe assembly. The system and its yield sequence is illustrated in Fig. 6 . Since this system is installed at the collar, it will protrude into the excavation as much as its $0.25 \mathrm{~m}$ (10 in.) length, affecting headroom. The length of the tail will be reduced by the yielding of the system. The tail length will be $0.15-0.20 \mathrm{~m}$ (6-8 in.) when the collar has completely yielded.

\section{TENSILE TESTS}

General description of testing: Each system was laboratory tested over its prescribed yield range in a $530 \mathrm{kN}(120,000 \mathrm{lb}$.) capacity Baldwin test machine. Tests were in-line, direct tensile tests controlled by displacement. Load and displacement data were collected each second. The data were displayed as a load versus displacement plot in real time and also recorded by the PC based data acquisition system for later analysis. The system was calibrated to ASTM E-4-93 requirements with reference standards verified by ASTM E-74-91 standards.

Tests were limited by the approximate $0.2 \mathrm{~m} \mathrm{(} 7 \mathrm{in}$.) stroke of the machine and testing was interrupted as required to reset the test machine. In the case of some of the Yielding Cable Bolts, three resets were necessary to pull the system through the $0.51 \mathrm{~m}$ ( $20 \mathrm{in}$.) yield range.

Rigging: The Load Indicators and Yielding Collars were tested using threaded bars as the bolt system. The anchor ends of the cables on the Slip Nut and Yielding Cable Bolt systems were fitted with a swaged nut. In all tests, both ends of the systems tested were installed next to rigid, flat bearing plates. While the anchor end remained fixed, the platen with the yielding component was displaced which loaded the system. 
Test Sequence: After rigging was completed and the bolts were installed in the test machine, testing commenced. Tests were controlled by displacement and typically proceeded at 0.003 $\mathrm{m} / \mathrm{min}$. $(0.1 \mathrm{in} / \mathrm{min}$.). Variations or exceptions to this rate are noted in the Results section of this paper.

\section{RESULTS}

Slip Nut System: Testing was initiated and controlled by a displacement rate of approximately $0.013 \mathrm{~m} / \mathrm{min}$. (0.5 in $/ \mathrm{min}$.). Rigging was slightly different in that a $0.15 \mathrm{~m} \times 0.15 \mathrm{~m} \times 0.01 \mathrm{~m}(6 \mathrm{in}$. $\mathrm{x}$ 6 in. $x 3 / 8$ in.) bearing plate was used at the collar end of the bolt. Each bolt yielded or slipped at or near the expected $133 \mathrm{kN}$ (30 kip) value. Yield is dynamic and sudden. All slipped with uniform peaks dropping off to zero or near zero load before reloading. Bolt tails tended to dog-leg beyond the slip nut during load application. A notable curvature was exhibited or retained by the tail bar after testing was completed. A plot of Test DSI\#1 data (Fig. 7) is typical for each of the tests performed. Pertinent loads and displacements for each test are presented in Table 1.

Fig. 7: Bolt Test DSI\#1

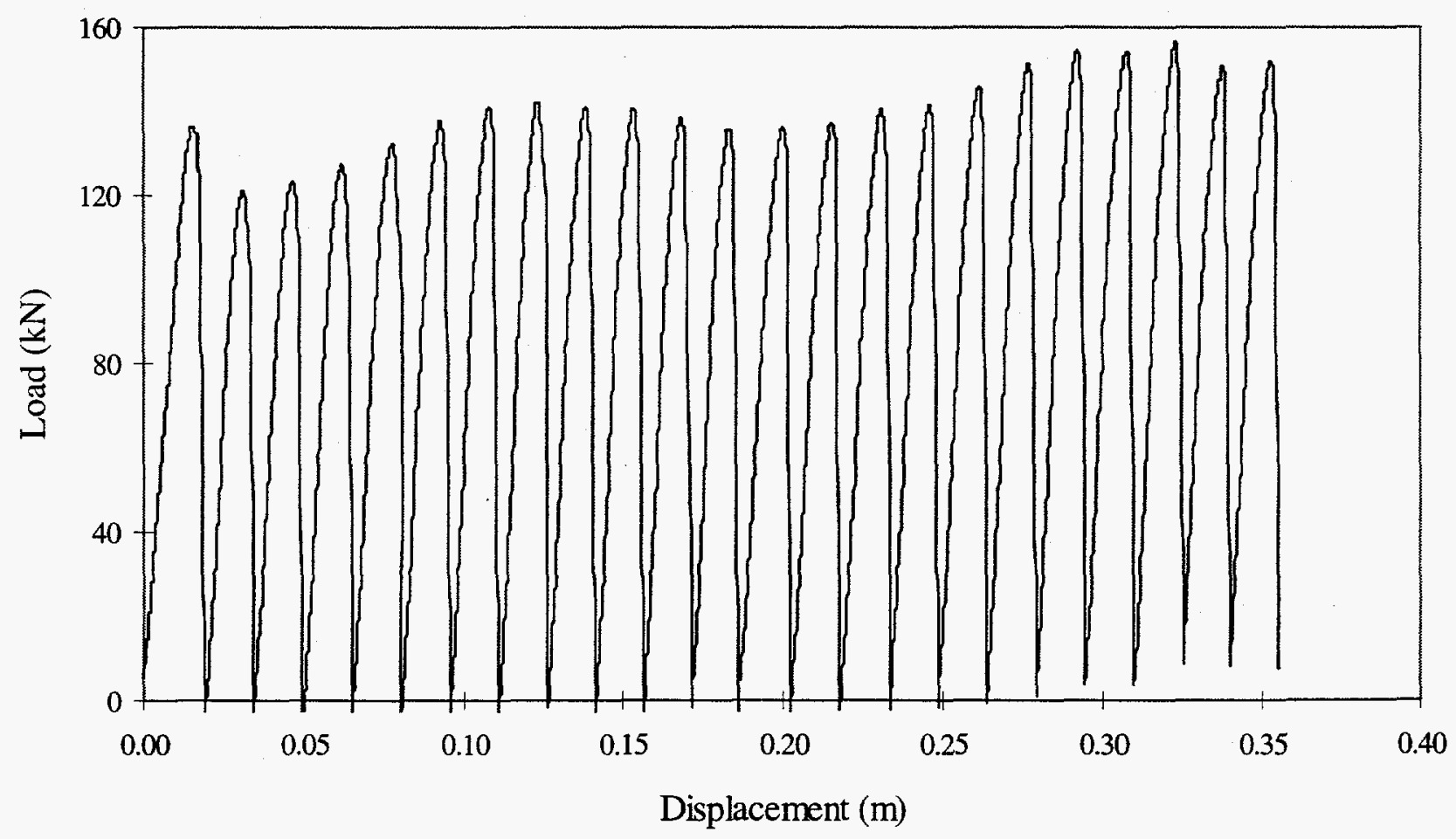


Table 1: Slip Nut Test Data

\begin{tabular}{ccc}
\hline Test Designator & Yield Range & Total Tested Displacement \\
\hline DSI\#1 & $120-156 \mathrm{kN}(27-35 \mathrm{kip})$ & $0.36 \mathrm{~m}(14 \mathrm{in})$ \\
DSI\#2 & $142-151 \mathrm{kN}(32-34 \mathrm{kip})$ & $0.32 \mathrm{~m}(13 \mathrm{in})$ \\
DSI\#3 & $138-160 \mathrm{kN}(31-36 \mathrm{kip})$ & $0.35 \mathrm{~m}(13 \mathrm{in})$ \\
DSI\#4 & $129-147 \mathrm{kN}(29-33 \mathrm{kip})$ & $0.35 \mathrm{~m}(14 \mathrm{in})$ \\
DSI\#5 & $120-142 \mathrm{kN}(27-32 \mathrm{kip})$ & $0.34 \mathrm{~m}(13 \mathrm{in})$ \\
\hline
\end{tabular}

Titan Load Indicator: In all cases the bottom groove (closest to the flat end) yielded first, followed by the center groove and finally the top groove. After the yield of the center groove, during the subsequent reloading sequence, the base, or flat end, yielded and flared around the bolt nut. This action produced additional yield beyond that expected by groove crush. A typical loading curve for the tests is shown in Figure 8. Pertinent yield loads and total yield for each test are summarized in Table 2.

Fig. 8: Test TLI\#5

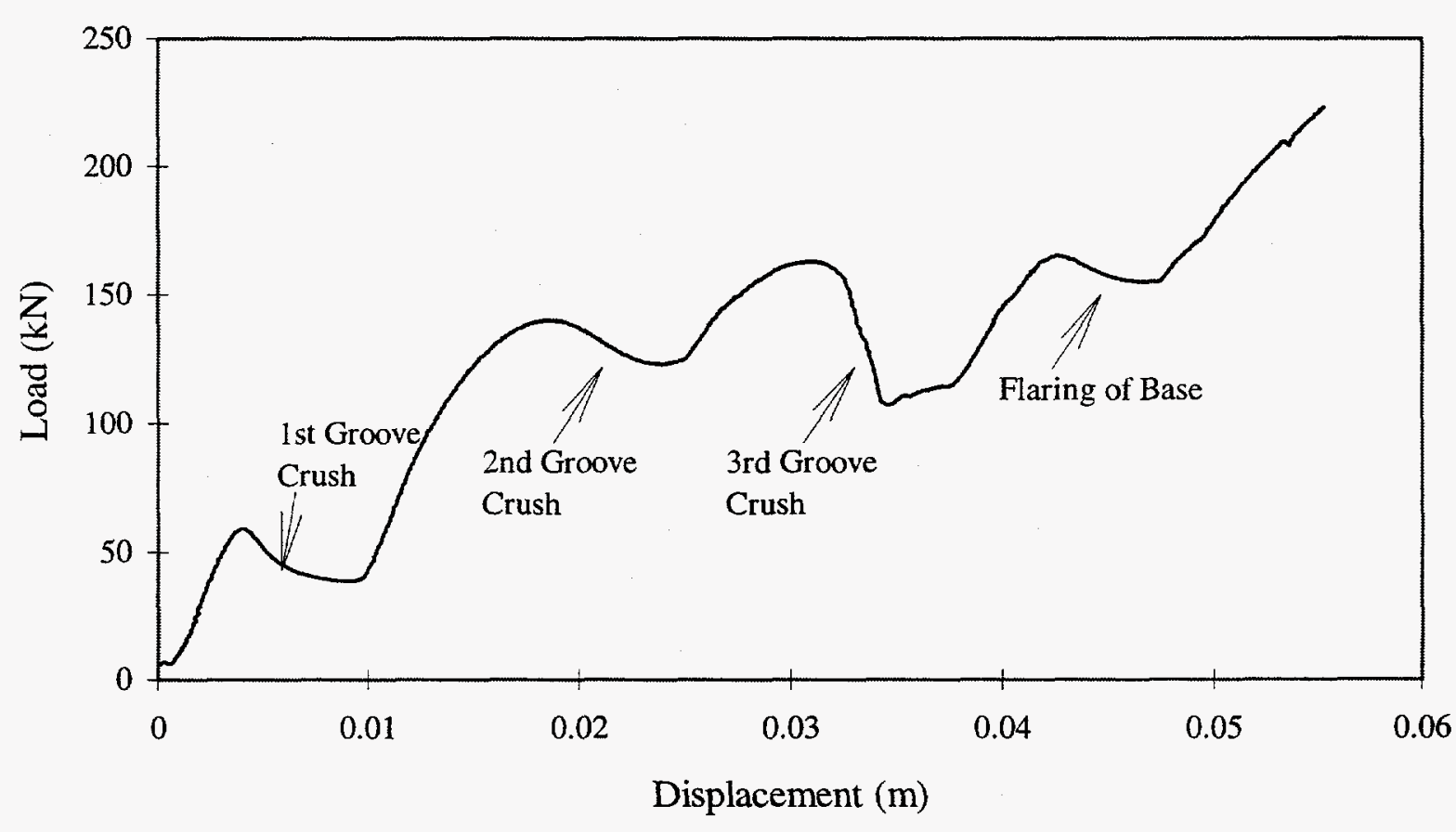


The yield load associated with each groove was consistent between indicators tested. Both load indication and yield was exhibited by the system. The use of a rock bolt in a tension test instead of crushing the indicator in a compression test influenced the data collected because of the elastic response associated with the bolt. It was not determined how the indicator may respond to postyield loads higher than those tested in the lab.

\section{Table 2: Titan Load Indicator Test Data}

\begin{tabular}{ccccc}
\hline $\begin{array}{c}\text { Test } \\
\text { Designator }\end{array}$ & $\begin{array}{c}\text { Yield } \\
\text { Groove 1 }\end{array}$ & $\begin{array}{c}\text { Yield } \\
\text { Groove 2 }\end{array}$ & $\begin{array}{c}\text { Yield } \\
\text { Groove 3 }\end{array}$ & $\begin{array}{c}\text { Total } \\
\text { Yield* }\end{array}$ \\
\hline TLI\#1 & $52 \mathrm{kN}(12 \mathrm{kip})$ & $157 \mathrm{kN}(35 \mathrm{kip})$ & $163 \mathrm{kN}(37 \mathrm{kip})$ & $48 \mathrm{~mm}(1.89 \mathrm{in})$. \\
TLI\#2 & $62 \mathrm{kN}(14 \mathrm{kip})$ & $154 \mathrm{kN}(35 \mathrm{kip})$ & $178 \mathrm{kN}(40 \mathrm{kip})$ & $49 \mathrm{~mm}(1.95 \mathrm{in})$. \\
TLI\#3 & $57 \mathrm{kN}(13 \mathrm{kip})$ & $140 \mathrm{kN}(31 \mathrm{kip})$ & $173 \mathrm{kN}(39 \mathrm{kip})$ & $50 \mathrm{~mm}(1.97 \mathrm{in})$. \\
TLI\#4 & $60 \mathrm{kN}(13 \mathrm{kip})$ & $144 \mathrm{kN}(32 \mathrm{kip})$ & $175 \mathrm{kN}(39 \mathrm{kip})$ & $47 \mathrm{~mm}(1.85 \mathrm{in})$. \\
TLI\#5 & $59 \mathrm{kN}(13 \mathrm{kip})$ & $140 \mathrm{kN}(31 \mathrm{kip})$ & $163 \mathrm{kN}(37 \mathrm{kip})$ & $49 \mathrm{~mm}(1.92 \mathrm{in})$. \\
& & & \\
* Includes the elasticity of the No. 7 threaded bar used in testing. Total yield displacement of each \\
indicator was approximately 0.03 m (one inch).
\end{tabular}

Yielding Cable Bolt: In all cases elastic loading was followed by the yielding of the system. Each cable bolt yielded and continued to provide support after yielding. In general, peak load was reached after about $0.20 \mathrm{~m}$ ( $8 \mathrm{in}$.). If production bolts have the cable tail pulled completely into the slide chamber at the outset, they should develop peak loading within about the first $10 \mathrm{~mm}(0.4 \mathrm{in}$.) as demonstrated in all reloading cycles after resetting the stroke of the test machine (Fig. 9).

Once the peak load was neared, loading held steady at approximately $+/-5 \%$ of the peak. The yield characteristics were typically smooth with no dynamic slips or jumps observed in the data. No component failures were noted. A typical loading curve is shown in Figure 9. Pertinent parameters, loads, and displacements for the bolts tested are summarized in Table 3. 
Fig. 9: Bolt Test RMB \#3

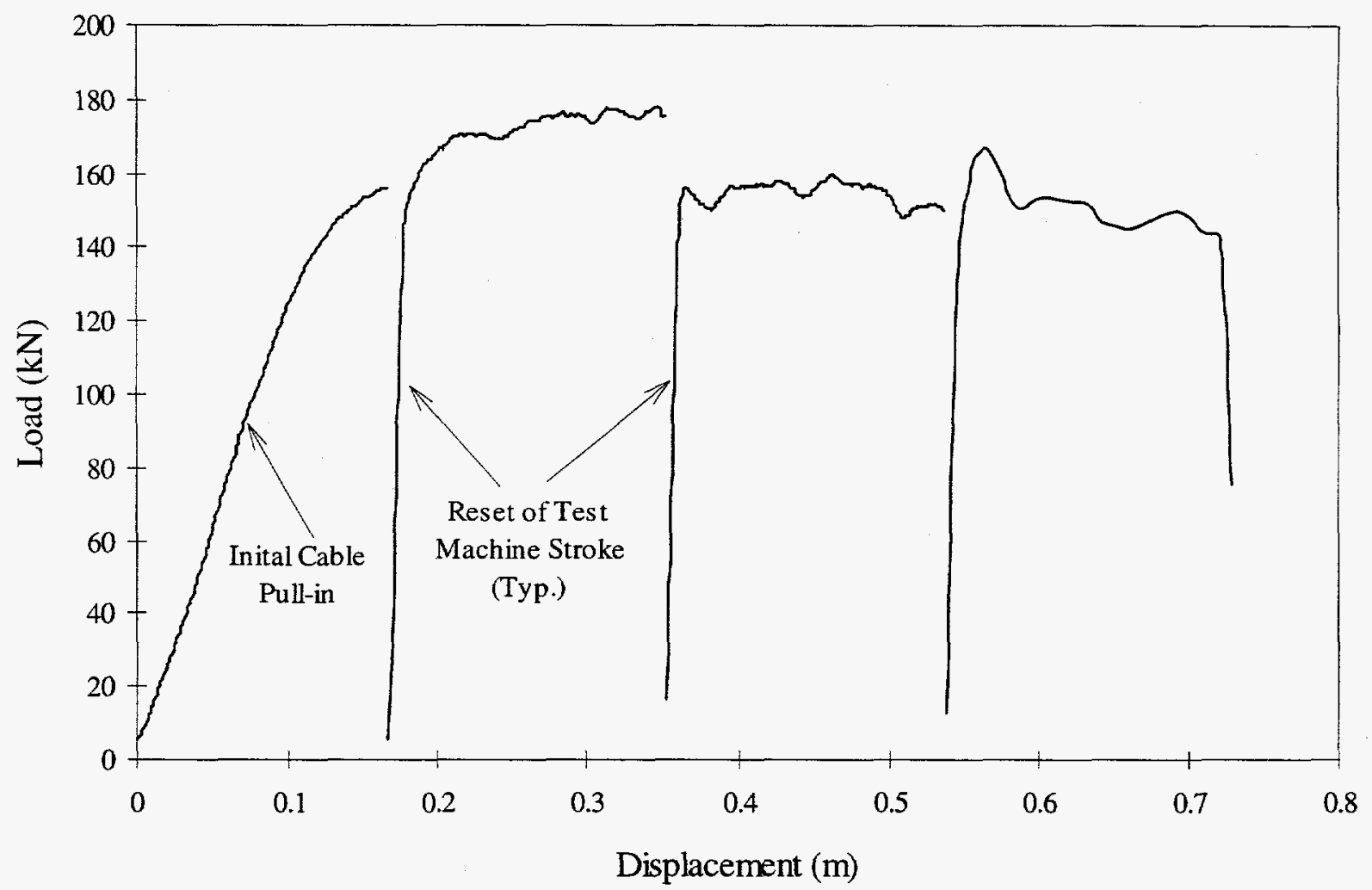

Table 3: Yielding Cable Bolt Test Data

\begin{tabular}{ccccc}
\hline $\begin{array}{c}\text { Test } \\
\text { Designator }\end{array}$ & Design Yield Load & Actual Peak Load & Average Peak Load & Displacement \\
\hline T5 & $93 \mathrm{kN}(21 \mathrm{kip})$ & $95 \mathrm{kN}(21 \mathrm{kip})$ & $85 \mathrm{kN}(19 \mathrm{kip})$ & $0.51 \mathrm{~m}(20 \mathrm{in})$. \\
$\mathrm{T} 4$ & $116 \mathrm{kN}(26 \mathrm{kip})$. & $105 \mathrm{kN}(24 \mathrm{kip})$ & $88 \mathrm{kN}(20 \mathrm{kip})$ & $0.49 \mathrm{~m}(19 \mathrm{in})$. \\
$\mathrm{T} 2$ & $141 \mathrm{kN}(32 \mathrm{kip})$ & $141 \mathrm{kN}(32 \mathrm{kip})$ & $127 \mathrm{kN}(28 \mathrm{kip})$ & $0.45 \mathrm{~m}(18 \mathrm{in})$. \\
$\mathrm{T} 1$ & $142 \mathrm{kN}(32 \mathrm{kip})$ & $137 \mathrm{kN}(31 \mathrm{kip})$ & $112 \mathrm{kN}(25 \mathrm{kip})$ & $0.50 \mathrm{~m} \mathrm{(20} \mathrm{in.)}$ \\
$\mathrm{T} 3$ & $173 \mathrm{kN}(39 \mathrm{kip})$ & $178 \mathrm{kN}(40 \mathrm{kip})$ & $163 \mathrm{kN}(37 \mathrm{kip})$ & $0.75 \mathrm{~m} \mathrm{(29} \mathrm{in.)}$
\end{tabular}


RE/SPEC Yielding Collars: Testing was begun and controlled by a displacement rate of approximately $0.1 \mathrm{in} . / \mathrm{min}$. $(0.002 \mathrm{~m} / \mathrm{min}$.). The first two tests, Tests RSI\#1 and RSI\#2 were performed on the older style collar. The older style collar is indicated by a flare in the large diameter pipe at the "knuckle" where the two pipes are initially installed. Both exhibited an elastic load buildup over approximately the first half inch $(0.01 \mathrm{~m})$ of displacement with yield occurring with under one inch $(0.02 \mathrm{~m})$ of displacement (Fig. 10). Tests RSI\#3-5 were performed on the newer style collar. The newer style collar is indicated by no noticeable difference in diameter in the larger pipe. In each of these tests, elastic buildup was noted over approximately the first half inch $(0.01 \mathrm{~m})$ of displacement followed by a severe release or yielding. After yielding commenced, load remained steady over the entire yielding length of the collar (Fig. 10).

Yield characteristics associated with Tests 1 and 2 may be preferable to those associated with Tests 3-5. In areas with adequate headroom, this system could be used as a yielding system. It was not determined how the residual system responds to the subsequent load build-up after full yielding of the system. Plots of the RSI\#2 and RSI\#5 test data are presented in Figure 10. Test RSI\#2 represents the typical loading curve for Tests 1 and 2 and Test RSI\#5 represents the typical loading curve for Tests 3-5. Pertinent load and displacement data for each test is provided in Table 4.

Figure 10: Typical Plots - RE/SPEC Yielding Collar

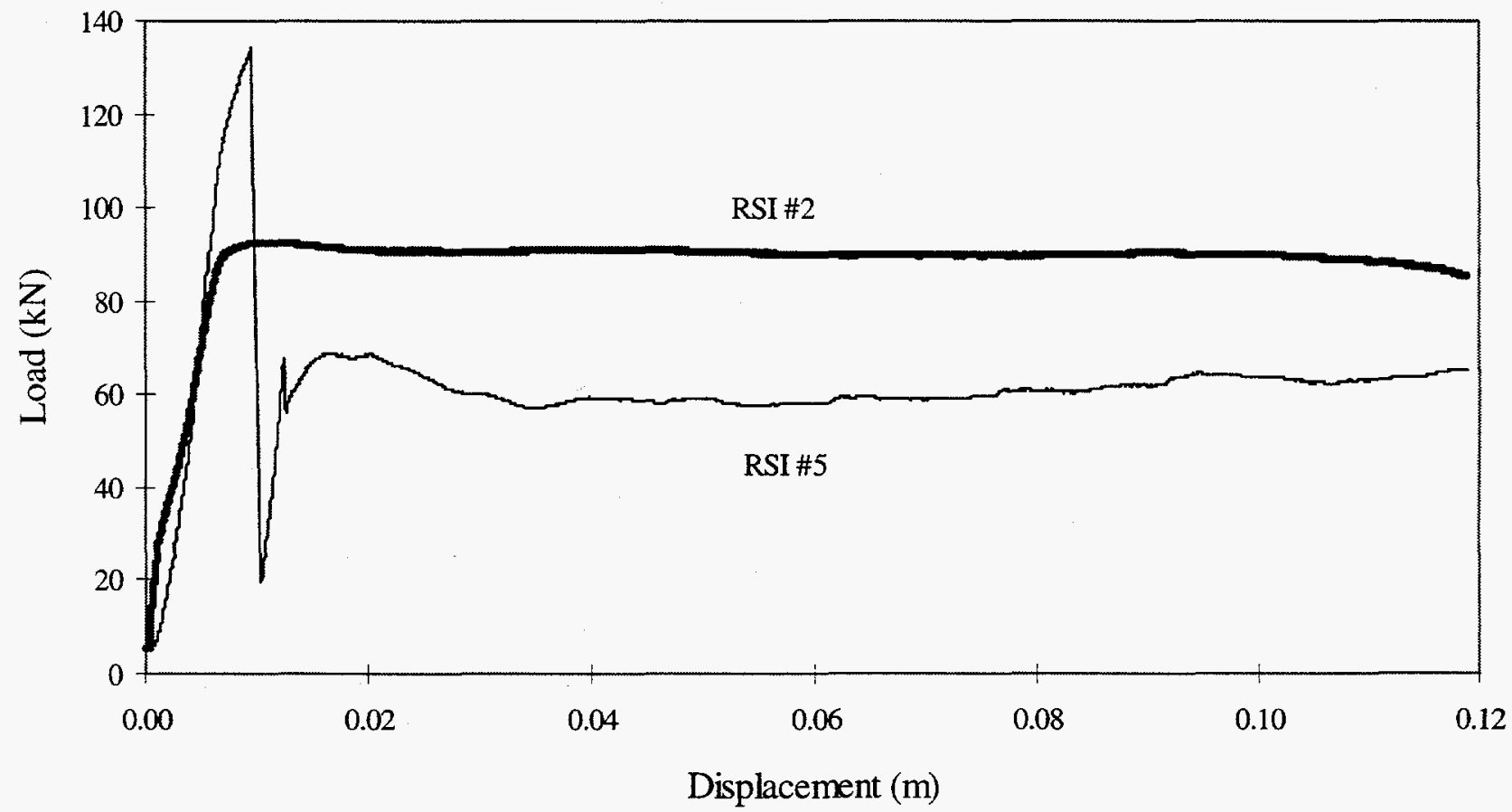


Table 4: RE/SPEC Yielding Collar Test Data

\begin{tabular}{cccc}
\hline Test Designator & Peak @ Yield & $\begin{array}{c}\text { Post Yield (Approx. } \\
\text { Ave.) }\end{array}$ & Total Yield* \\
\hline RSI\#1 & $100 \mathrm{kN}(22 \mathrm{kip})$ & $87 \mathrm{kN}(20 \mathrm{kip})$ & $0.116 \mathrm{~m}(4.6 \mathrm{in})$. \\
RSI\#2 & $93 \mathrm{kN}(21 \mathrm{kip})$ & $89 \mathrm{kN}(20 \mathrm{kip})$ & $0.130 \mathrm{~m}(5.1 \mathrm{in})$. \\
RSI\#3 & $149 \mathrm{kN}(33 \mathrm{kip})$ & $67 \mathrm{kN}(15 \mathrm{kip})$ & $0.130 \mathrm{~m}(5.1 \mathrm{in})$. \\
RSI\#4 & $137 \mathrm{kN}(31 \mathrm{kip})$ & $67 \mathrm{kN}(15 \mathrm{kip})$ & $0.132 \mathrm{~m}(5.2 \mathrm{in})$. \\
RSI\#5 & $134 \mathrm{kN}(30 \mathrm{kip})$ & $62 \mathrm{kN}(14 \mathrm{kip})$ & $0.119 \mathrm{~m}(4.7 \mathrm{in})$. \\
\hline
\end{tabular}

*Includes the elasticity of the bolt used in testing. Total yield displacement of each collar was approximately four inches.

\section{CONCLUSION}

Each system was tested over its prescribed yield range under laboratory conditions. Because each system produces yield through ductile material behavior, system yield points are typically not as predictable or consistent as a stress-strain curve with the material in the elastic region. However, each system yielded according to its design. Yield loads were typically within $10 \%$ of their design level.

Where headroom must be preserved, those systems that do not project into the opening will be favored over the others. Although each system can be modified or tailored to yield at the level desired by a user, the yielding cable bolt design may offer more flexibility in this regard.

Economics will always play a major role in selection of support systems. Although pricing is not discussed herein, typically the more complex systems will cost more. Since the yielding systems are typically more difficult to produce than most standard, rigid bolts, they will probably be more expensive. However, where ground movement or extended opening life necessitates multiple generations of support, these systems may be the most economic option. Certainly the transition to the use of a yielding system will be more accepted and probably more economical if current installation equipment can be used and if the implementation is not in conflict with existing support plans.

Safety should be enhanced by using yielding systems if they remain intact in areas where moving ground may cause failure in standard rigid bolts or systems. This should be true for tensile loads, modeled in this testing, and loads generated by offsetting strata, if the combined biaxial stresses do not exceed the ultimate strength of the bolt. Although beyond the scope of this testing, with further development and testing, some of the systems may have good potential for application in the control of ground exposed to rockbursts or bumps. 
It is recognized that the behavior of a system installed in moving ground may differ from that observed in the lab. Operators must proceed with caution, meeting MSHA regulations for ground control. However, the laboratory data indicate that these systems and others like them show promise in providing better tools to the industry to maintain or control active and moving ground.

\section{REFERENCES}

Ischebeck Titan, 1994, “Rock Bolts for Tunnel Construction” Sales Brochure, p.6.

Gillespie, Doug, 1993, conversation with J.D. VandeKraats held at Rocky Mountain Bolt Company in Salt Lake City. December 10, 1993.

Processing and final preparation of this report was performed by the Waste Isolation Pilot Plant Management and Operating Contractor for the U.S. Department of Energy under Contract No. DE-AC04-86AL31950. 